\title{
Removal of a non-steroidal anti-inflammatory drug (Piroxicam) in an aqueous medium by an agricultural by-product
}

\author{
Nora Samghouli ${ }^{1, *}$, Boutaina Regraguy ${ }^{1}$, Fatima-Zahra Abahdou ${ }^{1}$, Karima Azoulay ${ }^{1}$, Imane Bencheikh ${ }^{1}$, Jamal \\ Mabrouki ${ }^{1}$ and Souad El Hajjaji ${ }^{1, *}$ \\ ${ }^{1}$ Laboratory of Spectroscopy, Molecular, Modeling, Materials, Nanomaterials, Water and Environment, (LS3MNWE), Department of \\ Chemistry, Faculty of Sciences, Mohammed V University in Rabat, Av Ibn Battouta, B.P. 1014, Rabat 10000, Morocco
}

\begin{abstract}
The presence of pharmaceuticals in the environment has increased. These pollutants are toxic and non-biodegradable. Piroxicam (PRX) is a non-steroidal anti-inflammatory drug that ends up in wastewater via pharmaceutical industry activities and human being consumption. This work aimed to study the pharmaceutical pollutant removal from wastewater using agricultural by-products as low-cost adsorbent material. Different parameters were studied, such as time, initial adsorbate concentrations, and temperature. The study of the initial concentration-effect shows that the greatest amount of adsorbed is observed in low concentrations. The temperature has shown a negative effect in this study. The kinetics show that after $45 \mathrm{~min}$, the equilibrium is obtained; that means the exhaustion of all active sites. The representative model of this adsorption is the Langmuir isotherm according to the regression coefficient, which is equal to 0.99 . The natural abundance of this material and the low cost of investment could offer a good alternative to other more expensive adsorbents such as activated carbon.
\end{abstract}

Keywords: Adsorption; Wastewater; agricultural by-product; Low-cost material; Piroxicam

\section{Introduction}

In recent years, Modernization and population growth have contributed to the contamination of water sources by new chemical products, which have led to a large number of environmental problems [1, 2]. Contamination of water by Pharmaceuticals is an increasing problem across the world [3-5]. The pollution of water by pharmaceuticals poses a serious threat to human health and the environment $[6,7]$, affecting a wide range of aquatic species in a variety of ways, including erratic behavior, reproduce and development abnormal, and a lack of metamorphosis [8]. The emergence of pharmaceutical substances and their metabolites in the environment occurs through the excretion of these pharmaceuticals through urine [9-11]. Therefore, the existence of a suitable technique for the removal of these pollutants from wastewater is a challenge. One of these pharmaceuticals is piroxicam, which is used as a non-steroidal anti-inflammatory drug to reduce symptoms of fever, rheumatic disease, and pain [12]. This medication is consumed in large quantities each year and is getting it in wastewater in the amounts of $\mathrm{ng} / \mathrm{L}$ or $\mu \mathrm{g} / \mathrm{L}$, which indicate a high level of environmental toxicity according to the literature [13].

Several treatment techniques are used for to remove organic contaminants from wastewater, such as biological oxidation, coagulation, flocculation, and sedimentation [14], advanced oxidation processes (AOP), photo- Fenton [15], electrochemical oxidation / degradation [16, 17], membrane processes [18], and adsorption [19]. Despite the availability of all these techniques for the removal of organic pollutants, the adsorption process remains the best because of its high efficiency and effectiveness, low cost, easy to operate [20]. Moreover, adsorption can also remove pollutants without any generation of hazardous by-products $[16,21]$. Adsorption is usually done with activated carbon, which has a big specific surface area but also comes at a high price. Other materials have been shown in several studies that are alternatives, more effective, and low-cost, such as orange peel [22], Rice Husk [23], Banana peel [24], and date palm leaves [25].

The present study aims to carry out an experimental investigation to remove piroxicam from an aqueous solution using treated artichoke waste as an adsorbent alternative. Kinetic and isotherm studies were performed to determine the equilibrium time and the adsorption type.

\footnotetext{
*Corresponding authors: nora_samghouli@um5.ac.ma or souad.elhajjaji@um5.ac.ma
} 


\section{Materiels and methods}

\subsection{Materiels}

\subsubsection{Adsorbent}

In a flask containing $\mathrm{NaOH}(2 \%)$ solution, the cleaned, artichoke waste was immersed and stirred for $2 \mathrm{~h}$ at $50^{\circ} \mathrm{C}$. The collected sample was filtered, rinsed with distilled water. The samples were then treated for 1 hour at $70^{\circ} \mathrm{C}$ with sodium hypochlorite $(\mathrm{NaClO})(3.7 \% \mathrm{w} / \mathrm{v})$ in a ratio of $(0.5: 3 \mathrm{v} / \mathrm{v}) \mathrm{NaClO} / \mathrm{H}_{2} \mathrm{O}$. The recovered sample was filtered and washed repetitively until it reached neutral $\mathrm{pH}$, then it was dried in the open-air [26].

\subsubsection{Adsorbate}

Piroxicam is a non-steroidal anti-inflammatory, analgesic, and antipyretic drug having a long biological half-life [27]. The piroxicam was used as a model contaminant without any previous purification.

100 milligrams of piroxicam were dissolved in $100 \mathrm{~mL}$ of distilled water to make a stock solution. Then, four dilute solutions were made from the stock solution: $10 \mathrm{mg} / \mathrm{L}, 20 \mathrm{mg} / \mathrm{L}, 30 \mathrm{mg} / \mathrm{L}$, and $40 \mathrm{mg} / \mathrm{L}$.

\subsection{Methods}

\subsubsection{Analysis method}

The study of piroxicam adsorption onto treated artichoke waste (TAW) was carried out in a static system. A mass of TAW was introduced into a volume of $50 \mathrm{~mL}$ of piroxicam, the mixture was stirred $(500 \mathrm{rpm} / \mathrm{min})$ at room temperature. After liquid-solid (Piroxicam-TAW) separation by centrifugation (3500 rpm for $20 \mathrm{~min}$ ). The residual concentration of the filtrates was analysed by UV-1600 spectrophotometer at 334nm [27].

The evolution in adsorption efficiency was carried out either by determining the adsorption yield of piroxicam (R(\%)); or by calculating the adsorbed amount $(\mathrm{Q}(\mathrm{mg} / \mathrm{g}))$. The following equations were used to calculate the adsorption yield and the amount of adsorption [28-30]:

$$
\begin{aligned}
\mathrm{R}(\%) & =\frac{\mathrm{Ci}-\mathrm{Cf}}{\mathrm{Ci}} \times 100 \\
\mathrm{Qm} & =\frac{\mathrm{Ci}-\mathrm{Cf}}{\mathrm{m}} \times \mathrm{V}
\end{aligned}
$$

Where: $C_{i}$ is the initial and $C_{f}$ is the final piroxicam concentrations $(\mathrm{mg} / \mathrm{L}), \mathrm{m}$ is the mass of treated artichoke waste $(\mathrm{TAW})(\mathrm{g})$, and $\mathrm{V}$ is the volume $(\mathrm{L})$.

\subsubsection{Piroxicam adsorption onto TAW}

\subsubsection{Kinetic runs}

The adsorption kinetics of piroxicam onto treated artichoke waste was studied by adding $1 \mathrm{~g}$ of TAW in $1 \mathrm{~L}$ of piroxicam solution. These suspensions were mixed continuously for 75 minutes at room temperature. At programmed time intervals, aliquots of the supernatant $(3.6 \mathrm{ml})$ were taken, centrifuged, and analyzed by UV-VIS spectrophotometry.

\subsubsection{Determination of adsorption isotherms}

To study the piroxicam's concentration effect on the adsorption via treated artichoke waste, a piroxicam stock solution of $40 \mathrm{mg} / \mathrm{L}$ was prepared. To accomplish piroxicam adsorption isotherms, all the parameters were maintained constant except the concentration which was varied between $5-40 \mathrm{mg} / \mathrm{L}$. The suspensions were shaken for 45 min (time sufficient to reach the equilibrium), then centrifuged (20 min at $3500 \mathrm{rpm}$ ) and analyzed with UV-Visible spectrophotometry.

\section{Results and discussion}

\subsection{Adsorption of piroxicam onto TAW}

\subsubsection{Effect of contact time on piroxicam removal}


Optimization of the adsorption time is one of the most important actions to get a high removal efficiency under specific operating conditions. This is also interesting from an economic standpoint because it suggests maximizing drug adsorption while minimizing time.

To study the adsorption kinetics of piroxicam onto TAW, the experiment was conducted under these operating conditions [31] (Adsorbent dose $=2 \mathrm{~g} / \mathrm{L}, \mathrm{pH}=3, \mathrm{~T}=20^{\circ} \mathrm{C}$, and $[$ Piroxicam $]=10 \mathrm{mg} / \mathrm{L}$ ). Samples were taken at regular time intervals to determine the amount adsorbed quantity of piroxicam. The results obtained are shown in Figure 1.

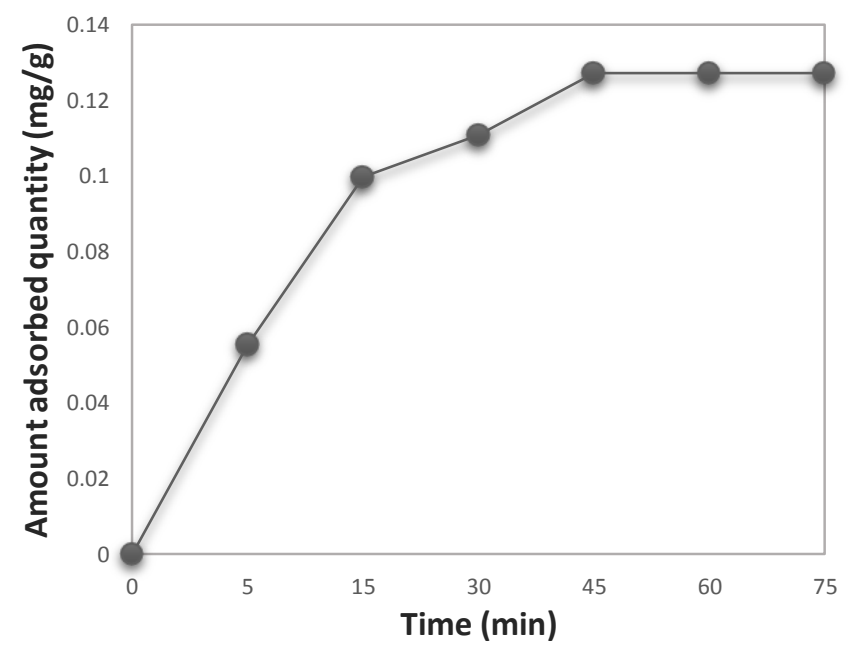

Fig. 1. Contact time effect on the piroxicam adsorption onto TAW.

The contact time effect on the piroxicam adsorption shows that during the first 15 minutes, the removal of piroxicam via adsorption onto TAW increases rapidly. It continues to rise at a slower rate than in the first minutes until it reaches equilibrium at 45 minutes. The high availability of active sites on the surface of TAW may explain the rapid increase in piroxicam removal in the first phase of treatment.

These phenomena can be explained by exhausting all active sites which exist on the surface of the studied material (TAW) $[32,33]$. We may also deduce from the curve that the amount adsorbed quantity of TAW is $0.13 \mathrm{mg} / \mathrm{g}$ in $45 \mathrm{minutes}$. The TAW adsorbent is so effective to remove organic medicines from wastewater.

\subsubsection{Adsorption kinetic models}

The plots of the pseudo-first and pseudo-second-order kinetic models of piroxicam adsorption on TAW are shown in Figure 2.

The mathematical expressions of each model and the values of the regression coefficients, as well as the parameters of these kinetic models, are grouped in Table 1.
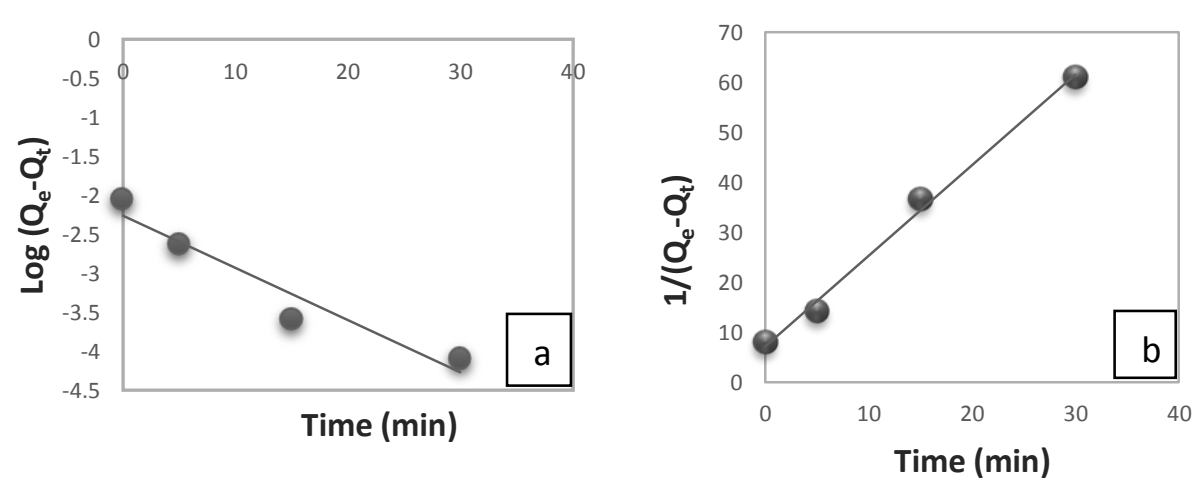

Fig. 2. Kinetic models of piroxicam adsorption onto TAW: pseudo-first-order (a); pseudo-second-order (b)

Table 1. Kinetic model formulas and parameters of the piroxicam adsorption onto TAW

\begin{tabular}{|l|l|l|}
\hline Kinetic model formulas & Parameters & Piroxicam/TAW \\
\hline Pseudo-first-order [34] & & 0.93 \\
$\log \left(\mathrm{q}_{\mathrm{e}}-\mathrm{q}_{\mathrm{t}}\right)=\log \left(\mathrm{q}_{\mathrm{e}}\right)-\mathrm{K}_{1} \frac{K}{2.303} \mathrm{t} \quad(3)$ & $\mathrm{R}^{2}\left(\mathrm{~min}^{-1}\right)$ & 0.16 \\
\cline { 2 - 3 } & $\mathrm{q}_{\mathrm{e}}(\mathrm{cal})(\mathrm{mg} / \mathrm{g})$ & 0.10 \\
\hline
\end{tabular}




\begin{tabular}{|l|l|l|}
\hline & $\mathrm{q}_{\mathrm{e}}(\exp )(\mathrm{mg} / \mathrm{g})$ & 0.13 \\
\hline Pseudo-second-order [35] & $\mathrm{R}^{2}$ & 0.99 \\
\cline { 2 - 3 }$\frac{1}{\mathrm{Qe}-\mathrm{Qt}}=\frac{1}{\mathrm{Qe}}+\mathrm{K}_{2} \mathrm{t} \quad(4)$ & $\mathrm{k}_{1}(\mathrm{~g} / \mathrm{mg} \cdot \mathrm{min})$ & 1.81 \\
\cline { 2 - 3 } & $\mathrm{q}_{\mathrm{e}}$ (cal) $(\mathrm{mg} / \mathrm{g})$ & 0.14 \\
\cline { 2 - 3 } & $\mathrm{q}_{\mathrm{e}}(\exp )(\mathrm{mg} / \mathrm{g})$ & 0.13 \\
\hline
\end{tabular}

Where: $\mathrm{q}_{\mathrm{e}}$ and $\mathrm{q}_{\mathrm{t}}$ the adsorbed amount of piroxicam at a time $(\mathrm{t})$ and at equilibrium time $(\mathrm{mg} / \mathrm{g})$ respectively; $\mathrm{t}$ : contact time $(\mathrm{min}) ; \mathrm{K}_{1}, \mathrm{~K}_{2}$ : rate constants for pseudo $1^{\text {st }}(1 / \mathrm{min})$ and pseudo $2^{\text {nd }}\left(\mathrm{g} \cdot \mathrm{mg}^{-1} \cdot \mathrm{min}^{-1}\right)$ kinetic models respectively.

As shown in table 1, it can be seen that, in the case of first-order kinetics, the experimentally determined equilibrium adsorbed quantity is different from the calculated one. On the other hand, the experimentally determined equilibrium adsorbed quantity is adjacent to the one calculated using the second-order kinetics model. This model applies well in the case of the adsorbent/adsorbate systems studied, given the values obtained for the coefficients of determination $\mathrm{R}^{2}$ which are very near to 1 . This model implies chemisorption, which includes electron exchanges at the solid-liquid interface [36, $37]$.

\subsubsection{Isotherm models}

\subsubsection{Initial concentration effect of piroxicam}

The initial pollutant concentration can alter the efficiency of an adsorbent to remove pollutants, which is dependent on the combination of pollutant concentration and available binding sites on the adsorbent's surface [38, 39].

To study the effect of the initial concentration of piroxicam in an aqueous medium, different concentrations of piroxicam were changed with fixation of the remaining factors (adsorbent dose $=2 \mathrm{~g} / \mathrm{L}, \mathrm{pH}=3, \mathrm{~T}=20^{\circ} \mathrm{C}$ ), then, the solutions were mixed and stirred. These solutions were shaken until they approached equilibrium (time $=45 \mathrm{~min}$ ). The effect of the piroxicam concentration onto TAW is shown in Fig. 3.

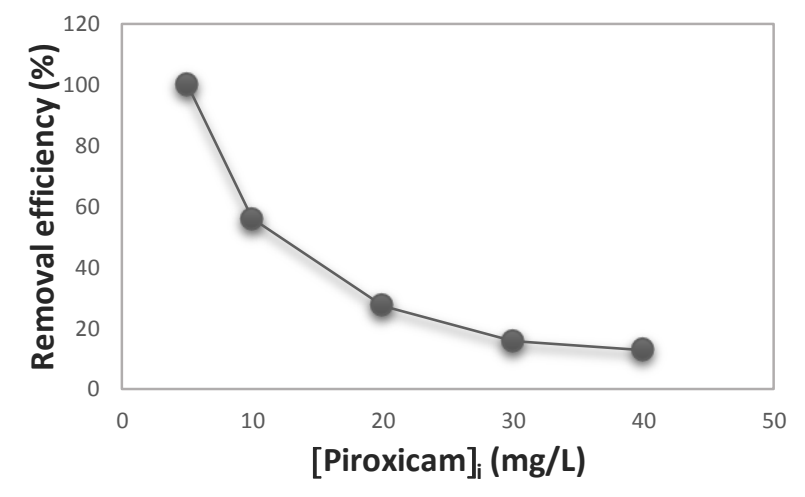

Fig. 3. Initial concentration effect on the adsorption of piroxicam onto TAW

As seen in Fig. 3, the initial concentration of piroxicam affects negatively the removal efficiency of TAW, so that the adsorption rate decreases with the increasing concentration of piroxicam. The adsorption rate of the TAW is decreased rapidly by $44.05 \%$ by increasing the concentration from 5 to $10 \mathrm{mg} / \mathrm{L}$; meanwhile, the adsorption rate of the TAW adsorbent was decreased by $28.70 \%$ when the piroxicam concentration was increased from 10 to $20 \mathrm{mg} / \mathrm{L}$, and then decreased slightly by $14.58 \%$ from 20 to $40 \mathrm{mg} / \mathrm{L}$.

\subsubsection{Adsorption isotherm models}

Adsorption isotherms are often used to determine maximum pollutant adsorption capacities and to identify the type of adsorption. The results, processed according to the mathematical models of Langmuir and Freundlich, allowed us to determine the maximum adsorption capacity and the adsorption parameters [40].

The curves of the piroxicam adsorption isotherm models onto TAW are shown in Fig. 4.a and b respectively for the Langmuir and Freundlich models and the corresponding formulas and parameters are grouped in Table 2. 

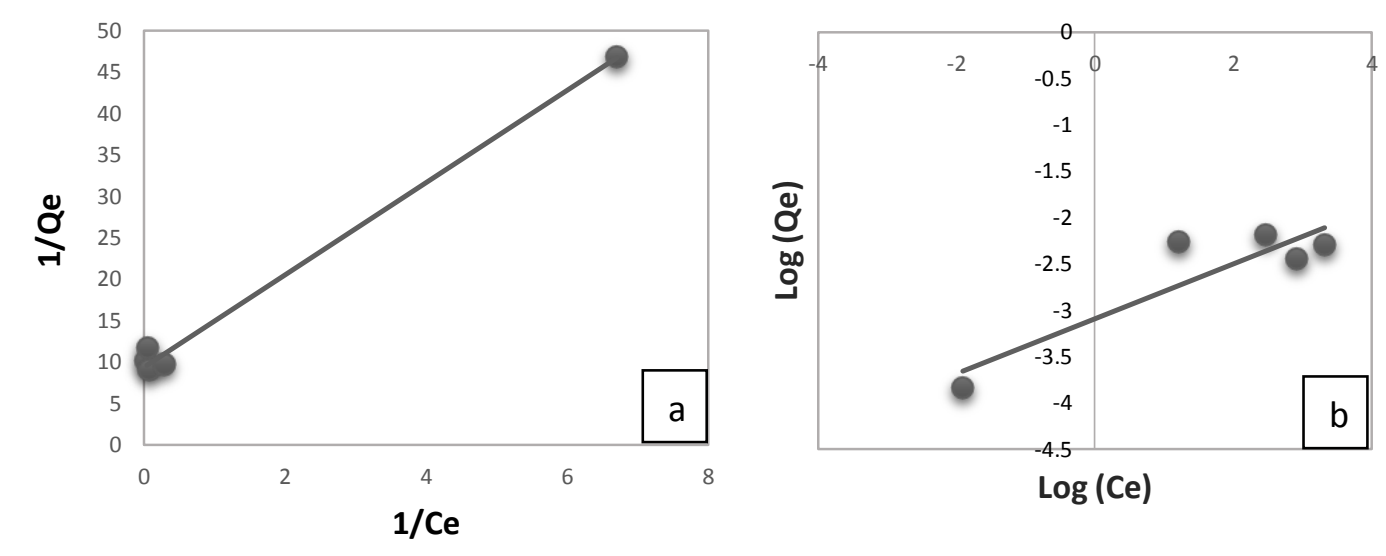

Fig. 4. (a) Langmuir and (b) Freundlich adsorption isotherms of piroxicam onto TAW

Table 2. isotherm model formulas and parameters of the piroxicam adsorption onto TAW

\begin{tabular}{|l|l|l|}
\hline Adsorption isotherm model formulas & Parameters & Piroxicam/TAW \\
\hline $\begin{array}{l}\text { Langmuir [41] } \\
\frac{1}{\mathrm{Qe}}=\frac{1}{\mathrm{Qm}}+\frac{1}{\mathrm{Qm} . \mathrm{KL} \cdot \mathrm{Ce}}(5)\end{array}$ & $\mathrm{R}^{2}$ & 0.99 \\
\cline { 2 - 3 } & $\mathrm{Q}_{\mathrm{m}}(\mathrm{mg} / \mathrm{g})$ & 20.33 \\
\cline { 2 - 3 } & $\mathrm{K}_{\mathrm{L}}$ & 0.41 \\
\cline { 2 - 3 } & $\mathrm{R}_{\mathrm{L}}$ & 0.11 \\
\hline $\begin{array}{l}\text { Freundlich [42] } \\
\text { LogQe }=\operatorname{LogKF}+\frac{1}{\mathrm{nf}} \log \mathrm{Ce}(6)\end{array}$ & $\mathrm{R}^{2}$ & 0.98 \\
\cline { 2 - 3 } & $\mathrm{K}_{\mathrm{F}}$ & 76.01 \\
\cline { 2 - 3 } & $1 / \mathrm{n}$ & 0.41 \\
\hline
\end{tabular}

Where: $\mathrm{q}_{\mathrm{e}}$ and $\mathrm{q}_{\mathrm{m}}$ are the adsorption quantity of piroxicam at equilibrium time and maximum adsorption quantity (mg/g) respectively; $K_{L}$ and $K_{F}$ are Langmuir constant $\left(L \cdot \mathrm{mg}^{-1}\right)$ and Freundlich constant $\left(\mathrm{mg}^{(1-\mathrm{n})} \mathrm{L}^{\mathrm{n}} \cdot \mathrm{g}^{-1}\right)$ respectively; $\mathrm{R}_{\mathrm{L}}$ : Separation parameter of equilibrium $R L=\frac{1}{1+b \times c 0}[43] ; 1 / \mathrm{n}_{\mathrm{f}}$ : Factor of heterogeneity;

The values of the regression coefficients indicate that the adsorption process of piroxicam by TAW is described favourably by the Langmuir isotherm (linear regression coefficient $\mathrm{R}^{2}$ which is very close to unity). This finding suggests that adsorption occurs in a monolayer on homogeneous surfaces [44, 45].

\subsubsection{Initial temperature effect}

The temperature was altered between 20 and $60^{\circ} \mathrm{C}$ in this study to assess the temperature effect on the adsorption of piroxicam onto TAW. 


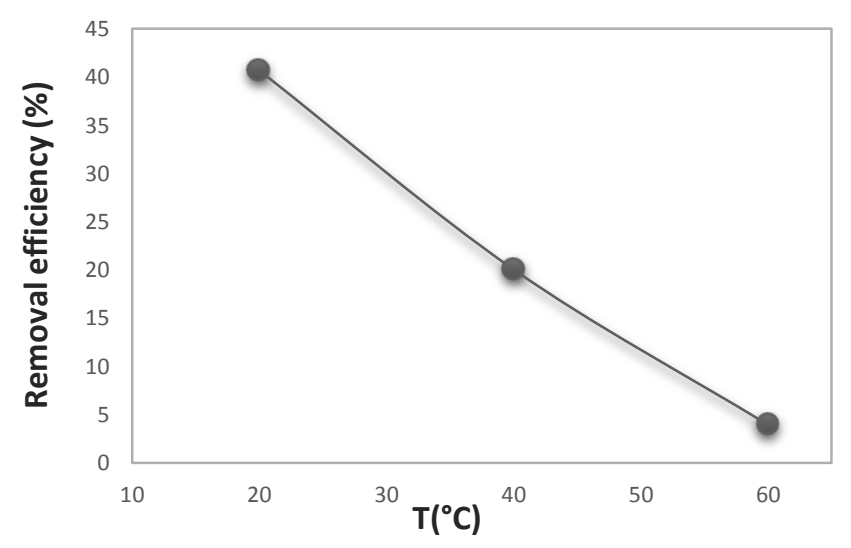

Fig. 5. Temperature effect on the adsorption of piroxicam onto TAW

The temperature effect on piroxicam adsorption onto the TAW (Fig. 5) reveals that the adsorption decreases rapidly $(20.66 \%)$ between $20^{\circ} \mathrm{C}$ and $40^{\circ} \mathrm{C}$ and then decreases by $16.11 \%$ when the temperature rises to $60^{\circ} \mathrm{C}$. Therefore, the temperature has a negative effect on the adsorption process in this study.

\section{Conclusion}

This work was intended as a contribution to the elimination of pharmaceutical products present in water. This study carried out on synthetic water gave results that prove the feasibility of adsorption of this residue (piroxicam) as well as the operating conditions of adsorption of this pharmaceutical product in water. It would be interesting to study the behavior of other pharmaceutical molecules and especially to apply it in real waters (waste from drug manufacturing plants, drinking water, etc.) to search for and eliminate residues of pharmaceutical products that can harm human beings.

In this study, different parameters were studied, the adsorption kinetics, the study of isotherms, the initial concentration effect of the adsorbent, and the effect of temperature. The results obtained allow the following conclusions:

- The study of the initial concentration-effect shows that the greatest quantity adsorbed is observed for low concentrations.

- The kinetics show that after $45 \mathrm{~min}$, equilibrium is reached; this means the exhaustion of all active sites that exist at the TAW interface.

- The representative model is the Langmuir isotherm according to the regression coefficient which is equal to 0.99 . The natural abundance of this material and the low capital cost could offer a good alternative to other more expensive adsorbents.

\section{References}

1. S. M. Siddeeg, M. A. Tahoon, and F. Ben Rebah, Mater. Res. Express 7, 012001 (2019)

2. M. Kumar, B. P. Tripathi, and V. K. Shahi, J. Hazard. Mater. 172, 1041 (2009)

3. E. Guinea, C. Arias, P. L. Cabot, J. A. Garrido, R. M. Rodríguez, F. Centellas, and E. Brillas, Water Res. 42, 499 (2008)

4. E. Brillas, I. Sirés, and M. A. Oturan, Chem. Rev. 109, 6570 (2009)

5. I. Sirés, E. Brillas, M. A. Oturan, M. A. Rodrigo, and M. Panizza, Environ. Sci. Pollut. Res. 21, 8336 (2014)

6. B. Kasprzyk-Hordern, R. M. Dinsdale, and A. J. Guwy, Water Res. 43, 363 (2009)

7. T. Mackulak, L. Birošová, I. Bodík, R. Grabic, A. Takáčová, M. Smolinská, A. Hanusová, J. Híveš, and M. Gál, Sci. Total Environ. 539, 420 (2016)

8. C. I. Kosma, D. A. Lambropoulou, and T. A. Albanis, Sci. Total Environ. 466-467, 421 (2014)

9. A. Bavili Tabrizi and N. Seyyedeh Tutunchi, Adv. Pharm. Bull. 3, 37 (2013)

10. S. Papoutsakis, Z. Afshari, S. Malato, and C. Pulgarin, J. Environ. Chem. Eng. 3, 2002 (2015)

11. R. Zhang, P. Sun, T. H. Boyer, L. Zhao, and C.-H. Huang, Environ. Sci. Technol. 49, 3056 (2015)

12. (n.d.)

13. S. M. Siddeeg, A. Amari, M. A. Tahoon, N. S. Alsaiari, and F. B. Rebah, Alex. Eng. J. 59, 905 (2020)

14. C. Duran, D. Ozdes, A. Gundogdu, and H. B. Senturk, J. Chem. Eng. Data 56, 2136 (2011)

15. J. M. Salman, V. O. Njoku, and B. H. Hameed, Chem. Eng. J. 174, 41 (2011)

16. Md. J. K. Ahmed, M. Ahmaruzzaman, and R. A. Reza, J. Colloid Interface Sci. 428, 222 (2014)

17. M. C. Somasekhara Reddy, L. Sivaramakrishna, and A. Varada Reddy, J. Hazard. Mater. 203-204, 118 (2012)

18. A. Altınışık, E. Gür, and Y. Seki, J. Hazard. Mater. 179, 658 (2010) 
19. D. Smiljanić, B. de Gennaro, A. Daković, B. Galzerano, C. Germinario, F. Izzo, G. E. Rottinghaus, and A. Langella, J. Environ. Manage. 286, 112168 (2021)

20. Y. Dai, Q. Sun, W. Wang, L. Lu, M. Liu, J. Li, S. Yang, Y. Sun, K. Zhang, J. Xu, W. Zheng, Z. Hu, Y. Yang, Y. Gao, Y. Chen, X. Zhang, F. Gao, and Y. Zhang, Chemosphere 211, (2018)

21. I. Ali, Mohd. Asim, and T. A. Khan, J. Environ. Manage. 113, 170 (2012)

22. I. C. Afolabi, S. I. Popoola, and O. S. Bello, Chemom. Intell. Lab. Syst. 203, 104053 (2020)

23. T. D. Pham, T. T. Bui, T. T. Trang Truong, T. H. Hoang, T. S. Le, V. D. Duong, A. Yamaguchi, M. Kobayashi, and Y. Adachi, J. Mol. Liq. 298, 111981 (2020)

24. M. Patel, R. Kumar, C. U. Pittman, and D. Mohan, Environ. Res. 111218 (2021)

25. F. Saremi, M. R. Miroliaei, M. Shahabi Nejad, and H. Sheibani, J. Mol. Liq. 318, 114126 (2020)

26. I. Bencheikh, K. Azoulay, J. Mabrouki, S. El Hajjaji, A. Moufti, and N. Labjar, Chem. Data Collect. 31, 100597 (2021)

27. A. Bachhav, S. Ahire, and A. Jadhav, Int. J. Pharm. Sci. Res. 10, 811 (2019)

28. I. Bencheikh, K. Azoulay, J. Mabrouki, S. El Hajjaji, A. Moufti, and N. Labjar, Chem. Data Collect. 31, 100597 (2021)

29. K. Azoulay, I. Bencheikh, J. Mabrouki, N. Samghouli, A. Moufti, A. Dahchour, and S. E. Hajjaji, Int. J. Environ. Anal. Chem. 0, 1 (2021)

30. Y. Tan, Z. Cheng, Y. Liu, X. Gao, S. Liu, and Z. Shen, Chemosphere 280, 130577 (2021)

31. N. Samghouli, I. Bencheikh, K. Azoulay, F-Z. Abahdou, J. Mabrouki, and S. El Hajjaji, EAI/Springer Innov. Commun. Comput., XIV,166 (2022)

32. S. Dawood, T. K. Sen, and C. Phan, Water. Air. Soil Pollut. 225, 1818 (2013)

33. I. Bencheikh, K. Azoulay, J. Mabrouki, S. El Hajjaji, A. Dahchour, A. Moufti, and D. Dhiba, Sci. Afr. 9, e00509 (2020)

34. S. Wang and H. Li, Dyes Pigments 72, 308 (2007)

35. Y. S. Ho, D. a. J. Wase, and C. F. Forster, Environ. Technol. 17, 71 (1996)

36. D. Mohan, K. P. Singh, and V. K. Singh, J. Hazard. Mater. 135, 280 (2006)

37. Suhas, P. J. M. Carrott, and M. M. L. Ribeiro Carrott, Bioresour. Technol. 98, 2301 (2007)

38. S. Sinha Ray, R. Gusain, and N. Kumar, in (2020), pp. 119-135

39. E. Malkoc and Y. Nuhoglu, J. Hazard. Mater. 127, 120 (2005)

40. Z. Meçabih, S. Kacimi, and B. Bouchikhi, Rev. Sci. Eau J. Water Sci. 19, 23 (2006)

41. J.-Z. Guo, B. Li, L. Liu, and K. Lv, Chemosphere 111, 225 (2014)

42. A. Mittal, J. Mittal, A. Malviya, and V. K. Gupta, J. Colloid Interface Sci. 344, 497 (2010)

43. N. Mohammadi, H. Khani, V. K. Gupta, E. Amereh, and S. Agarwal, J. Colloid Interface Sci. 362, 457 (2011)

44. L. El Fakir, M. Flayou, A. Dahchour, S. Sebbahi, F. Kifani-Sahban, and S. El Hajjaji, Desalination Water Treat. 1 (2015)

45. V. K. Gupta and T. A. Saleh, Environ. Sci. Pollut. Res. Int. 20, 2828 (2013) 